\title{
How state counter-industry campaigns help prime perceptions of tobacco industry practices to promote reductions in youth smoking
}

\author{
J C Hersey, J Niederdeppe, S W Ng, P Mowery, M Farrelly, P Messeri
}

Tobacco Control 2005;14:377-383. doi: 10.1136/tc.2004.010785

See end of article for authors' affiliations

Correspondence to:

Correspondence to:
James Hersey, PhD, RTI

International, $1615 \mathrm{M}$

Street, NW, Suite 740,

Washington, DC 20036,

USA; hersey@rti.org

Received 3 December 2004

Accepted 24 July 2005

\begin{abstract}
Objective: This study assessed the impact of state media campaigns that prominently feature counterindustry messages on youth cigarette smoking, beyond the effects of price, secular trends, tobacco control efforts, and the national truth ${ }^{\infty}$ campaign.

Methods: Rates of youth smoking were compared in three groups of states: (1) those with long funded counter-industry campaigns (California, Florida, and Massachusetts); (2) states with more recently funded counter-industry media campaigns (Indiana, Minnesota, Mississippi, and New Jersey); and (3) other states. An analysis was performed for a series of national telephone surveys of 12-17 year olds between 1999 and 2002, controlling for differences in demographic background, the price of cigarettes, and exposure to the national truth ${ }^{\circledR}$ campaign.

Results: Between 1999 and 2002, rates of current smoking and established smoking decreased significantly faster in states with established or more newly funded counter-industry campaigns than in other states. State counter-industry campaigns appear to prime, or make more salient, negative perceptions about tobacco industry practices.

Conclusion: Results highlight the value of continued state counter-industry campaigns.
\end{abstract}

S tates have implemented media campaigns in recent years as part of more comprehensive efforts to prevent the initiation of youth tobacco use. ${ }^{1}$ Several states, including California (CA; in 1989), Massachusetts (MA; in 1994), and Florida (FL; in 1998), launched campaigns using ads that highlight industry efforts to target teens and draw attention to tobacco industry denials about the addictive and harmful nature of their product These campaigns were accompanied by grassroots anti-tobacco activities at the community level, school based tobacco use prevention education (TUPE), anti-tobacco policy initiatives, and/or statewide cigarette excise tax increases. ${ }^{2-4}$ Results from state and national evaluations demonstrate that tobacco control expenditures are associated with lower per capita consumption of tobacco, ${ }^{3-7}$ and lower youth smoking rates. ${ }^{2}$ Longitudinal studies link media campaign exposure to lower rates of youth smoking initiation in Massachusetts and Florida. $^{8}{ }^{9}$

The American Legacy Foundation launched the national truth $^{\circledast}$ campaign, modelled after Florida's campaign, in February 2000. Studies demonstrate an association between campaign exposure and changes in tobacco related attitudes, intentions, and smoking behaviour. ${ }^{10}{ }^{11}$ The reported success of the counter-industry messages has also led other states, specifically, Mississippi (MS; 1999), Minnesota (MN; 2000), and Indiana (IN) and New Jersey (NJ; both in 2001), to launch well funded youth counter-industry campaigns.

None of these media campaigns has used counter-industry messages exclusively. For example, California, Florida, Massachusetts, and the national truth ${ }^{\circledast}$ campaign messages have drawn attention to the long term illness and mortality associated with tobacco use. The New Jersey and Minnesota efforts have included messages about secondhand smoke. Massachusetts and Mississippi have employed humorous messages about tobacco's social acceptability. ${ }^{10}$ There have also been changes over time in the relative emphasis that has been placed on counter-industry messages. ${ }^{6}{ }^{12-15}$ Nonetheless, all of these campaigns have featured counter-industry messages as a major theme.

In addition, none of these campaigns occurred in isolation from other tobacco control programme components. For example, youth led anti-tobacco groups in Florida (Students Working Against Tobacco, or SWAT), Minnesota (Target Market), and New Jersey (Reaching Everyone by Exposing Lies, or REBEL) used counter-industry themed messages to persuade youth to avoid cigarettes. The presence of well funded counter-industry media campaigns thus reflects broader, statewide efforts to disseminate counter-industry messages to teens.

State budget pressures have revived questions about the value of using state campaigns in addition to the national truth $^{\circledast}$ campaign. In particular, the action of some state legislators in diverting funds earmarked for tobacco prevention to non-health purposes suggests that legislators may be unconvinced of the value of the counter-industry approach to reducing youth smoking. ${ }^{16}{ }^{17}$ Questions also remain about how the effects of counter-industry campaigns are produced. Traditional behaviour change models ${ }^{18}{ }^{19}$ such as the health belief model, ${ }^{20}{ }^{21}$ social cognitive theory, ${ }^{22-24}$ the transtheoretical stages of change model, ${ }^{25-27}$ and the theory of reasoned action $^{28}$ propose that messages should attempt to change beliefs among the target population. An alternate theory, however, suggests that campaigns can change behaviour by priming or increasing the salience of particular beliefs. ${ }^{29-31}$

The concept of media priming assumes that people make decisions based on the information that is most salient. ${ }^{30}{ }^{32} \mathrm{~A}$ media campaign might draw attention to certain beliefs and

Abbreviations: CA, California; CDC, Centers for Disease Control and Prevention; FL, Florida; GRP, gross ratings point; IN, Indiana; LMTS, Legacy Media Tracking Survey; MA, Massachusetts; MN, Minnesota; MS, Mississippi; NJ, New Jersey; REBEL, Reaching Everyone by Exposing Lies; SWAT, Students Working Against Tobacco; TUPE, tobacco use prevention education 
thus alter the standards by which people make decisions. In the context of social marketing, priming effects might lead us to expect that counter-industry campaigns would prompt youth to place greater weight on negative perceptions of tobacco industry practices in making decisions about smoking. In addition, beliefs that are otherwise weakly associated with attitudes can have their linkages strengthened through exposure to messages targeting those beliefs. ${ }^{29}{ }^{30}$

This paper compares rates of decline in youth smoking between states with well funded counter-industry campaigns and other states. In addition, we examine two possible routes of counter-industry campaign effects: (1) the traditional behaviour change model, focusing on changes in counterindustry beliefs over time; and (2) the media priming model, focusing on changes in the salience of counter-industry beliefs over time.

\section{METHODS}

\section{Data source}

This study analysed five waves of nationally representative Legacy Media Tracking Survey (LMTS) data from autumn 1999 through to autumn 2002. The surveys oversampled African Americans, Hispanics, Asians, and youth in states with their own media campaigns. The samples were weighted to reflect the US population. ${ }^{33}$

We compared tobacco related beliefs and behaviour across three time periods: (a) period 1, from November 1999 to January 2000, before the launch of the national truth $^{\circledR}$ campaign (LMTS-1), included 3424 12-17 year olds; (b) period 2, from autumn 2000 to spring 2001 (LMTS-2 and LMTS-3), included 12967 12-17 year-olds; and (c) period 3, from spring 2002 to autumn 2002 (LMTS-5 and LMTS-7), included 10855 12-17 year olds (LMTS-4 and LMTS-6 were omitted because of inadequate samples in the states with counter-industry campaigns). The response rates of the surveys ranged from 52.3-56.7\%. Waves contained similar proportions in terms of sex, age, race/ethnicity, and weekly income. We made an additional, direct standardisation adjustment of the samples by state grouping, age, sex, and race/ethnicity so comparisons over time would allow us to present trends that controlled for differences in the demographic population of these states. Data collection procedures were approved by RTI International's institutional review board.

\section{Measures \\ State groupings}

We categorised states into three groups based on the message, expenditure, and length of their media campaign: (1) established campaign states, (2) newer campaign states, and (3) other states. States with "established" counterindustry campaigns spent at least $50 \%$ of the Centers for Disease Control and Prevention (CDC) recommended level on the campaign, and at least $15 \%$ of the total campaign expenses were on the media campaign. In addition, established campaign states included a youth component, had a major counter-industry message, and were initiated at least one year before the first LMTS conducted in late fall 1999. Three states-CA, FL, and MA—met these criteria.

States with "newer" campaigns had to fulfil similar criteria, except that their media campaign needed only to have been launched at least one year before the LMTS conducted in fall 2002. The four states that met this definition were IN, MS, MN, and NJ. We classified the other 43 states as non-campaign states, even though several had funded anti-tobacco media campaigns (for example, Arizona, Ohio). However, none of these campaigns used counterindustry messages as a prominent strategy, reached the required level of funding, or had been running for a sufficient length of time before the final survey period.

\section{Outcome measures}

\section{Smoking behaviour}

We compared changes over time in the prevalence of current smoking, defined as having smoked a cigarette one or more times in the past 30 days. ${ }^{34}$

\section{Perception of tobacco industry index}

We created a linear, additive scale of perceptions of tobacco industry practices, with the higher score denoting a more anti-tobacco position. This index (range 5-25; coefficient $\alpha=0.74$ ) consisted of five items measured (with one exception) on a scale from "strongly disagree" (1) to "strongly agree" (5): "Cigarette companies lie", "Cigarette companies try to get young people to smoke", "I would like to see cigarette companies go out of business", and "I would not work for a tobacco company". A fifth item, "How much do you like cigarette companies?", was assessed on a response scale from "I like them a lot" (1) to "I don't like them at all" (5).

\section{Perception of smoking index}

For purposes of comparison, we also created an index of smoking perceptions, with a higher score indicating a more anti-tobacco position. The index (range 5-25; coefficient $\alpha=0.51)$ consisted of five items on a scale from "strongly disagree" (reverse coded to 5 where appropriate) to "strongly agree" (reverse coded to 1 where appropriate) regarding beliefs about the health effects and social effects of smoking. The index contained the five items: "it is safe to smoke for a year or two" (reverse coded), "smoking can help keep your weight down" (reverse coded), "smokers have a harder time in spots", "people who smoke have more friends" (reverse coded), and "smoking makes people look cool or fit in" (reverse coded).

\section{Control variables}

All multivariate models included a variety of control variables that might confound observed counter-industry state effects, including sociodemographic characteristics (age, sex, race/ ethnicity, number of parents in the home, attendance at religious services, employment status, and average weekly earnings) and media use variables (average daily television hours, average daily radio hours).

We controlled for exposure to the national truth ${ }^{\circledR}$ campaign using gross ratings point (GRP) data, which reflect the overall "dose" of truth " campaign advertisements by television broadcast media market. ${ }^{35}$ The use of GRPs avoided issues of selection bias in media use and recall that can make it difficult to draw inferences about the direction of causality from confirmed awareness measures because attitudes toward tobacco could cause heightened awareness of the campaign. ${ }^{136}$ GRPs are free of this limitation because it is not possible for attitudes to influence GRPs. Also, prior research has demonstrated a relationship between GRP exposures to the truth campaign and beliefs and attitudes, and smoking behaviour. ${ }^{1136}$

To isolate the independent effects of counter-industry media campaigns, we measured and controlled for exposure to other elements of state tobacco control programmes. These included the amount of state tobacco excise taxes (variation by state and year), an index of state clean indoor air laws (variation by state and year), ${ }^{37}$ awareness of community antitobacco groups and participation in community anti-tobacco groups (variation across individuals), and exposure to TUPE in school (variation across individuals) as indicated by the agreement by respondents to two of the following three 
items: "During the past year, (1) were you taught in any of your classes about the effects of smoking, like it makes your teeth yellow, causes wrinkles, or makes you smell bad?"; (2) "Were you taught in any of your classes about the reasons why people of your age smoke cigarettes?"; and (3) "Did you practice ways to say no to cigarettes and/or tobacco in any of your classes, for example, by role playing?". Finally, we included control variables for the number of months since the baseline survey and the population by media market.

\section{Analytic approach}

\section{Analysis of state trends in youth smoking}

We graphically analysed trends over time in youth smoking in states with established counter-industry campaigns, states with newer counter-industry campaigns, and other states, using the direct standardisation of sampling weights described above to control for differences in age, sex, and race/ethnicity.

\section{Logistic regression model controlling for potential confounders}

Next, we ran a logistic regression to model the relationship between state residence and smoking behaviour with controls for potential confounders. Unfortunately, GRP data comparable to that obtained for the national truth ${ }^{\circledast}$ campaign were not available from the state campaigns. As a result, the main independent variable in the model was residence in a state that had a major counter-market media campaign. For these analyses, we combined "established" and "newer" campaign states into a single category to provide greater analytic power (preliminary analyses revealed similar coefficients for both state groups). The model included indicator variables for time period (period l omitted category), counter-industry campaign states (versus other states), and interaction terms between campaign states and time periods. The main effects term for counter-industry campaign state residence in the model controls for previously existing differences between counter-industry campaign states and other states, whereas the indicator variables for time period reflect model predicted trends in smoking behaviour within non-campaign states in the absence of any tobacco control programme components (including state taxes, clean indoor air policies, community and school events). The interaction terms tested for differences in the rate of change in current smoking by state group. We expected to observe a significant, negative effect of both the counter-industry state residence* period 2 and counter-industry state residence*period 3 variables on current smoking status to provide evidence of a campaign effect (see appendix).

\section{Possible cognitive pathways for campaign effects}

Next, we explored the attitudinal pathways by which changes in smoking status might have occurred. We assessed changes in tobacco industry perceptions and smoking related beliefs over time to explore pathways suggested by traditional behaviour change theory. ${ }^{20} 28$

We then examined the evidence for priming effects- the possibility that the association between perceptions of tobacco industry practices and smoking became stronger in states that had counter-industry campaigns. We did this by comparing changes over time in the strength of the relationship between campaign targeted beliefs (negative perceptions of tobacco industry practices) and smoking behaviour. If priming effects occurred, we expected to find a significantly greater increase over time in campaign states (compared with non-campaign states) in the strength of the relationship between campaign related beliefs and smoking status.

We ran separate logistic regression models for each state campaign group to predict smoking status using both

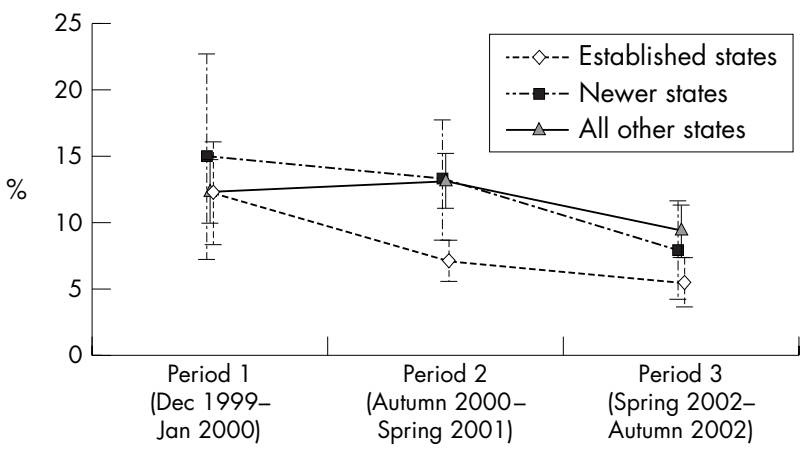

Figure 1 Percentage who are current smokers (smoked in the past 30 days). The difference between period 1 and period 3 was significant in established campaign states $(p<0.05)$. The difference in the rate of change between period 1 and period 3 for campaign states was statistically greater ( $p<0.05$, with a one tailed test) than non-campaign (all other) states without controlling for any other factors and was statistically different $(p<0.05)$ after controlling for age, sex, race/ ethnicity, and state excise taxes.

perception indices, while controlling for sociodemographic background (age, sex, race/ethnicity, home situation, religiosity, employment, and earnings), media use (hours of television, hours of radio), number of months since baseline, and state tobacco excise tax (see equation 2 in the appendix). We then used a Chow test to compare the changes in the odds ratios of the interaction terms between each index and the time period in the campaign states versus all other states. Chow tests assess whether coefficients estimated for one group are equal to the coefficients estimated for another group. ${ }^{38}{ }^{39}$ If the change over time in the strength of the odds ratio for tobacco industry perceptions in campaign states was significantly greater than the change in non-campaign states, we considered this result to be evidence of a priming effect.

To ensure that any priming effects did not simply reflect a broader pattern of changes in the salience of other, nontargeted smoking related beliefs, we replicated this analysis using the smoking perceptions index and smoking status. The evidence supporting an industry perceptions priming effect would be strengthened if a parallel pattern of results were not observed for the smoking perceptions index.

\section{RESULTS}

\section{Changes in the prevalence of smoking}

Figure 1 shows the prevalence over time for current smoking by state group. The established and newer campaign states had significantly greater declines in current smoking from 1999 to 2002 than other states. Specifically, current smoking rates declined by $55 \%$ in established campaign states (from $12.3 \%$ to $5.5 \%$ ) and by $47 \%$ in newer campaign states (from $15 \%$ to $7.9 \%$ ) over the study period, whereas observed declines in the remaining states were far less substantial (a $25 \%$ decline, from $12.5 \%$ to $9.4 \%$ ). The rate of decrease in campaign states (established plus newer) was roughly twice that of other states $(52.6 \% \vee 24.9 \%)$; this difference was significant $(p<0.05)$ after controlling for age, sex, race/ ethnicity, and state cigarette excise taxes.

\section{Sources of campaign effects}

Table 1 presents results from logistic regression models predicting current smoking as a function of being in one of the seven campaign states, time period, state time period interactions, and a host of potentially confounding variables. The significant interaction term coefficients in the current smoking model (campaign state ${ }^{*}$ period 2 and campaign state $^{*}$ period 3, both $\mathrm{p}<0.05$ ) indicate that the odds of being 
Table 1 Relationship between residence in a state with a counter-industry campaign and current smoking among 12-17 year olds over time

\begin{tabular}{llll}
\hline & \multicolumn{3}{l}{ Current smoking } \\
\cline { 2 - 4 } Independent variables & OR & SE & p Value \\
\hline Key variables & & & \\
Campaign state (CA, FL, MA, IN, MN, MS, & 1.426 & 0.327 & 0.122 \\
or NJ) & & & \\
Period 2 (autumn 2000 to spring 2001) & $1.631^{*}$ & 0.359 & 0.027 \\
Period 3 (2002) & 1.798 & 0.878 & 0.230 \\
Campaign state $\times$ period 2 & $0.580^{*}$ & 0.154 & 0.040 \\
Campaign state $\times$ period 3 & $0.488^{*}$ & 0.146 & 0.016 \\
Other tobacco control programme components & & & \\
Average real state cigarette excise tax & 0.998 & 0.001 & 0.217 \\
State clean indoor air index score & 0.960 & 0.034 & 0.254 \\
Aware of tobacco use prevention education & $0.628^{*}$ & 0.075 & 0.000 \\
Aware of community anti-tobacco groups & 0.944 & 0.129 & 0.672 \\
\hline
\end{tabular}

This model also included background variables (age, sex, race/ethnicity (African American, Hispanic, and other, where white was the omitted variable), religiosity, living with both parents, employment, average weekly earnings), media use (number of hours watching TV per week, number of hours listening to radio per week), cumulative gross rating points (GRPs) of exposure to the truth $^{\oplus}$ ads, and, as control variables, state population and the number of months since baseline.

The larger standard error at time 3 compared to time 1 and 2 is associated with design effects from oversampling campaign states.

*Significantly different from zero at the $p<0.05$ level.

$\mathrm{OR}$, odds ratio; $\mathrm{SE}$, standard error.

a current smoker were reduced significantly faster in states with counter-industry media campaigns than in states without these campaigns. These results were significant even when controlling for a host of potentially confounding variables including cumulative GRPs associated with national truth ${ }^{\circledR}$ campaign broadcast patterns.

Turning to other tobacco control programme components, only awareness of TUPE lessons reduced the odds of current smoking ( $p<0.001$ ), and the effects of state campaigns were significant even when awareness of TUPE was included in the model $(\mathrm{p}<0.05)$.

There was also a main effect for time (period 2), though opposite from the expected direction. Readers should keep in mind that this coefficient reflects model predicted trends in smoking behaviour in non-campaign states in the absence of any tobacco control programme related activities, including state excise taxes, clean indoor air policies, and community and school programmes. When these variables were controlled in the model, the positive sign for this coefficient suggests that smoking rates would have increased in noncampaign states in the absence of tobacco control efforts.

\section{Possible cognitive pathways for campaign effects}

Table 2 presents changes in tobacco industry perceptions and smoking perceptions over time. The analysis reveals few differences in the rate of campaign targeted belief change between campaign states and non-campaign states. In fact, the rate of campaign targeted belief change was slower in established campaign states compared with non-campaign states, suggesting that changes in these beliefs could not account for the observed differences in the rate of smoking declines. Changes in non-targeted beliefs (smoking perceptions) were negligible across state groupings.

Next we investigated the media priming model by analysing changes in the salience of counter-industry beliefs over time using a series of Chow tests. ${ }^{38}{ }^{39}$ As a preliminary step, we investigated whether the coefficients in logistic regressions were scaled by unequal error terms between the two groups (for example, unobserved heterogeneity). A test of equal variance found this was not a problem in our model.

Over time, negative perceptions about the tobacco industry showed an increasingly stronger relationship with smoking status in campaign states than in non-campaign states (table 3 ). Within campaign states, youth with more negative perceptions of the tobacco industry had 14\% lower odds of being current smokers in 1999 (odds ratio (OR) 0.86). By 2002 , their odds were $26 \%$ lower (OR 0.76). The rate of change was similar in established campaign states and in states with newer campaigns. By comparison, in noncampaign states, the magnitude of the odds ratios for the relationship between perceptions of industry beliefs and current smoking did not change significantly (OR 0.73 in period 1 and OR 0.77 in period 3). Chow tests for differences in trends revealed that campaign states had significantly stronger trends toward lower odds ratios than other states $(\mathrm{p}=0.005)$ for current smoking. Over time, negative beliefs about the tobacco industry showed an increasingly stronger relationship with smoking status in campaign states compared with non-campaign states. Moreover, the difference in the trends between campaign states and non-campaign states was significant.

A similar trend was seen for the relationship between smoking status and beliefs about smoking (table 4). However, these trends were not as strong as they were for perceptions of the tobacco industry, and the difference in the trends between campaign and non-campaign states was only

Table 2 Changes in perception indices over time among 12-17 year olds

\begin{tabular}{|c|c|c|c|c|}
\hline Type of state campaign & Period 1 & Period 2 & Period 3 & $\begin{array}{l}\% \text { point change from } \\
\text { period } 1-3\end{array}$ \\
\hline \multicolumn{5}{|l|}{$\begin{array}{l}\text { Perception of tobacco industry } \\
\text { index }(\alpha=0.74)\end{array}$} \\
\hline $\begin{array}{l}\text { Established states (CA, FL, } \\
\text { and MA) }\end{array}$ & $20.74 \dagger \S(20.39$ to 21.10$)$ & $21.24 \dagger \S(21.06$ to 21.42$)$ & 21.15 † (20.92 to 21.38$)$ & $1.98 \%$ \\
\hline $\begin{array}{l}\text { Newer states (IN, MS, MN, } \\
\text { and NJ) }\end{array}$ & $19.78 \S(19.15$ to 20.40$)$ & $20.41 \S(19.99$ to 20.83$)$ & $20.94(20.59$ to 21.29$)$ & $5.86 \% *$ \\
\hline $\begin{array}{l}\text { All other states } \\
\text { Perception of smoking index } \\
(\alpha=0.51)\end{array}$ & $19.64 \dagger(19.37$ to 19.90$)$ & $20.20+(19.98$ to 20.42$)$ & $20.69+(20.54$ to 20.85$)$ & $5.35 \% *$ \\
\hline $\begin{array}{l}\text { Established states (CA, FL, } \\
\text { and MA) }\end{array}$ & 20.39 (20.07 to 20.70$)$ & 20.78 (20.63 to 20.93 ) & $20.57 \dagger(20.34$ to 20.79$)$ & $0.88 \%$ \\
\hline $\begin{array}{l}\text { Newer states (IN, MS, MN, } \\
\text { and NJ) }\end{array}$ & 20.09 (19.30 to 20.88$)$ & 20.80 (20.57 to 21.03$)$ & 20.88 (20.57 to 21.20$)$ & $3.93 \%$ \\
\hline All other states & $20.56(20.36$ to 20.76$)$ & 20.81 (20.67 to 20.95$)$ & $20.78+(20.65$ to 20.90$)$ & $1.07 \%$ \\
\hline
\end{tabular}

Figures in parenthesis denote the $95 \%$ confidence interval.

*Significantly different at the $5 \%$ level.

†Significant difference at the $5 \%$ level between established states and other (non-campaign) states.

$\ddagger$ Significant difference at the $5 \%$ level between new campaign states and other (non-campaign) states.

$\S$ Significant difference at the $5 \%$ level between established campaign states and newer states. 
Table 3 Evidence for priming effects of the relationship between industry perceptions and smoking behaviour among 12-17 year olds

\begin{tabular}{lllll}
\hline & $\begin{array}{l}\text { Odds ratio of interaction term } \\
\text { between time period and } \\
\text { perception of the tobacco }\end{array}$ & $\begin{array}{l}\text { Difference } \\
\text { industry }\end{array}$ \\
\cline { 2 - 4 } $\begin{array}{l}\text { Type of state } \\
\text { campaign }\end{array}$ & Period 1 & Period 2 & Period 3 & (p value) \\
\hline $\begin{array}{l}\text { Current smoking } \\
\text { Established states }\end{array}$ & $0.835^{*}$ & $0.814^{*}$ & $0.733^{*}$ & \\
$\begin{array}{c}\text { Newer states } \\
\text { All campaign states }\end{array}$ & $0.821^{*}$ & $0.724^{*}$ & $0.767^{*}$ & \\
All other states & $0.862^{*}$ & $0.780^{*}$ & $0.756^{*}$ & $0.005 \dagger$ \\
\hline
\end{tabular}

This table shows the odds ratio between the index of beliefs about the tobacco industry and smoking in the past 30 days, controlling for media use and GRPs of exposure to truth ads in the media market, and demographic and background variables (for example, age, sex, race/ ethnicity, living with both parents, religiosity, employment, and weekly earnings) and a control variable for the number of months since baseline. *Odds ratio significantly different from zero at the $p<0.05$ level.

†Significant difference between campaign and non-campaign states, $\mathrm{p}<0.05$.

marginally significant $(p=0.051)$. Rather, the evidence for priming effects was most apparent for the beliefs about the tobacco industry that were most directly addressed by counter-industry campaign messages.

\section{DISCUSSION}

This paper provides additional evidence that well funded counter-industry campaigns can be an effective strategy to reduce youth smoking. States with well funded counterindustry campaigns had significantly larger declines in youth smoking rates than did states without these campaigns. Although this change could be attributable to factors other than the media campaigns, multivariate logistic regression models controlling for the effects of excise taxes, school based programmes, community anti-tobacco groups, and clean indoor air laws suggest that the campaigns exerted independent effects on reductions in smoking. Subsequent analyses suggest that these campaigns were effective in reducing smoking rates because they primed-or made more salient-perceptions about tobacco industry practices.

These results must be interpreted with limitations in mind. Our independent variable of exposure to state campaigns is simply residence in a state, controlling for potential exposure to other programme components. Reliance on a state level exposure variable did not allow us to analyse dose-response

Table 4 Evidence for priming effects of the relationship between smoking perceptions and smoking behaviour among $12-17$ year olds

\begin{tabular}{lllll}
\hline & \multicolumn{2}{l}{$\begin{array}{l}\text { Odds ratio of interaction term } \\
\text { between time period and } \\
\text { beliefs about smoking }\end{array}$} & $\begin{array}{l}\text { Difference } \\
\text { in trends } \\
\text { Type of state }\end{array}$ \\
\cline { 2 - 4 } campaign & Period 1 & Period 2 & Period 3 & (palue) \\
\hline $\begin{array}{l}\text { Current smoking } \\
\text { Established states }\end{array}$ & $0.804^{*}$ & $0.781^{*}$ & $0.760^{*}$ & \\
$\quad$ Newer states & $0.724^{*}$ & $0.796^{*}$ & $0.677^{*}$ & \\
All campaign states & $0.825^{*}$ & $0.793^{*}$ & $0.748^{*}$ & 0.051 \\
All other states & $0.756^{*}$ & $0.747^{*}$ & $0.723^{*}$ & \\
\hline
\end{tabular}

This table shows the odds ratio between the index of beliefs about smoking and smoking in the past 30 days, controlling for media use and GRPs of exposure to truth ${ }^{\circledast d}$ ad in the media market, and demographic and background variables (for example, age, sex, race/ethnicity, living with both parents, religiosity, employment, and weekly earnings) and a control variable for the number of months since baseline.

*Odds ratio significantly different from zero at the $p<0.05$ level.

\section{What this paper adds}

Despite reports of the initial success of early state counterindustry media campaigns, the continued impact of these campaigns, and of newer state campaigns, on youth smoking has not been well established. Legislators are asking difficult questions about the effect of states' efforts in addition to national anti-tobacco media campaigns. The mechanisms by which state media campaigns attain their effects are not well understood.

Study results indicate that youth smoking rates declined significantly more rapidly in states that had their own well funded counter-industry media campaign than in other states. Moreover, the study found that these effects occurred because the campaign appeared to prime, or make more salient, the campaign related beliefs.

relationships to state campaign exposure at the individual level. Since the ability to demonstrate association usually increases when there is greater variability in the independent variable, it is possible that our method produced conservative estimates of state campaign effects.

On the other hand, to the extent that measures of exposure to other programme components inadequately captured their effects, the state residence coefficient might overstate the impact of counter-industry media campaigns per se. The state counter-industry media campaigns occurred within the context of a comprehensive state campaign effort that included school based tobacco use prevention education, community prevention efforts, and clean indoor air laws. Our logistic regression models found independent contributions both for participation in TUPE and for residence in a state with a counter-industry media campaign. It thus seems reasonable to conclude that school based anti-tobacco activities are an important component of comprehensive state tobacco control efforts, a finding that is consistent with previous research. ${ }^{40-42}$

It is possible, however, that other programme components were not adequately measured. For example, some studies suggest that clean indoor air laws are important factors in reducing youth smoking rates, but we were unable to detect such an effect in our sample. ${ }^{43}$ Self reported awareness of community anti-smoking groups may inadequately capture the nature of these groups' influence. Measurement error related to other tobacco control programme components could artificially inflate the effect attributed to the media campaign. Furthermore, our criteria for counter-industry campaign state group inclusion included the requirement that the state spend at least $50 \%$ of the $\mathrm{CDC}^{\prime}$ s recommended tobacco control expenditures. As a result, campaign states also happen to be states that have invested considerable resources to tobacco control. It is thus possible that a portion of the observed effect associated with campaign state residence is attributable to the large, comprehensive nature of these state programmes. Nevertheless, the fact that we observed a stronger priming effect for campaign targeted beliefs than for other smoking perceptions suggests that counter-industry campaigns are an important component of these comprehensive state programmes.

We also assessed other factors that might otherwise have explained observed differences in the rate of youth smoking declines. Most notable was the launch of the national truth campaign. However, the confirmed awareness of exposure to truth $^{\circledast}$ ads was comparable in states with and without state campaigns, and the effects of state campaigns were still significant when we included those GRPs in our models. 
In addition, the key dependent variable in this study, self reported cigarette smoking, was gathered via a telephone survey. Telephone surveys of adolescents typically yield much lower estimates of cigarette smoking than school based surveys. However, we have found that, in general, trends for youth smoking in telephone surveys and in school based surveys are fairly similar, suggesting that the observed results are not a function of survey mode. ${ }^{44}$

Finally, we recognise that these results are based on repeated cross sectional surveys, not panel data. For example, this study found increasingly stronger associations between beliefs about the tobacco industry and smoking in campaign states over time. It is possible, however, that these differences could be influenced by differences in the content of antitobacco messages as the campaigns evolved (for example, additional resources devoted to counter-industry messages over time). Although the findings are supportive of the effects of counter-industry campaigns and the possibility of priming effects, longitudinal data can solidify the existence of causal relationships.

Overall, analyses provide evidence that well funded state counter-industry campaigns make an important contribution to the reduction of youth smoking rates. In so doing, state counter-industry media campaigns appear to complement the national truth ${ }^{\circledast}$ campaign. ${ }^{11}$ It also appears that one of the effects of these campaigns is an increase in the salience of anti-tobacco perceptions. Because this study is one of the first empirical demonstrations of priming effects in a public health campaign evaluation, the findings may be useful to investigate in other prevention efforts.

\section{ACKNOWLEDGEMENTS}

This study was conducted at RTI International with support from the American Legacy Foundation. The authors acknowledge helpful reviews by Jane Allen and Donna Valone of the American Legacy Foundation.

\section{Authors' affiliations \\ J C Hersey, J Niederdeppe, S W Ng, P Mowery*, M Farrelly, RTI \\ International, Washington, DC, USA \\ P Messerit, American Legacy Foundation, Washington DC}

${ }^{*}$ Current affiliation: Centers for Disease Control and Prevention †Current affiliation: Columbia University

Competing interest statement: This study was conducted at RTI International with support from the American Legacy Foundation. The authors had no financial interest in the campaigns described in this study and were not involved in campaign development.

RTI International is a trade name of Research Triangle Institute.

\section{APPENDIX}

\section{EQUATION 1 (USED IN TABLE 1)}

$\mathrm{P}$ (Current smoking) $=\alpha+\beta_{1} \mathrm{C}+\beta_{2} \mathrm{~T}+\beta_{3}\left(\mathrm{C}^{\star} \mathrm{T}\right)+\beta_{4} \mathrm{E}+\beta_{5} \mathrm{~S}+$ $\beta_{6} \mathrm{D}+\beta_{7} \mathrm{X}+\epsilon$

where:

- C denotes the indicator variable for being in a campaign state or not;

- $\mathrm{T}$ denotes the indicator variables for time period (baseline/1999 is the omitted/comparison time period);

- E denotes media exposure variables, such as cumulative gross rating points (GRPs) of exposure to the truth ${ }^{\circledR}$ ads in the local media market, TV hours, and radio hours;

- S denotes other tobacco control programme variables, such as state tobacco tax level, clean indoor air scores, exposure to tobacco use prevention education, and awareness of community antitobacco groups;
- D denotes demographic and background variables, such as age, sex, race/ethnicity, whether living with both parents, religiosity, whether employed, and earnings; and

- X denotes other control variables, including number of months since baseline and media market population.

\section{EQUATION 2 (USED IN TABLES 3 AND 4)}

Campaign states: $\mathrm{P}$ (Current smoking) ${ }_{\mathrm{C}=1}=\alpha+\gamma_{1} \mathrm{~T}$ $+\gamma_{2}\left(I^{\star} T\right)+\gamma_{3}\left(E^{\star} T\right)+\gamma_{4}\left(D^{\star} T\right)+\gamma_{5}\left(X^{*} T\right)+\epsilon$

Compared with other states: $\mathrm{P}$ (Current smoking) ${ }_{\mathrm{C}=0}=$ $\alpha+\gamma_{1} \mathrm{~T}+\gamma_{2}\left(\mathrm{I}^{*} \mathrm{~T}\right)+\gamma_{3}\left(\mathrm{E}^{*} \mathrm{~T}\right)+\gamma_{4}\left(\mathrm{D}^{*} \mathrm{~T}\right)+\gamma_{5}\left(\mathrm{X}^{*} \mathrm{~T}\right)+\epsilon$ where:

- C denotes whether in a campaign state or not;

- $\mathrm{T}$ denotes the indicator variables for time period (baseline/1999 is the omitted/comparison time period);

- I denotes the industry index (table 3 ) of the perceptions of smoking index (table 4);

- E denotes media exposure variables, such as TV hours and radio hours;

- D denotes demographic and background variables, such as age, sex, race/ethnicity, whether living with both parents, religiosity, whether employed, and earnings; and

- $\mathrm{X}$ denotes other control variables, including number of months since baseline.

\section{REFERENCES}

1 Farrelly MC, Niederdeppe J, Yarsevich J. Youth tobacco prevention mass media campaigns: past, present, and future directions. Tobacco Control 2003; 12(suppl I):i35-47.

2 Baver UE, Johnson TM, Hopkins RS, et al. Changes in youth cigarette use and intentions following implementation of a tobacco control program: findings from the Florida Youth Tobacco Survey, 1998-2000. JAMA 2000;284:723-8.

3 Biener L, Harris JE, Hamilton W. Impact of the Massachusetts tobacco control program: population based trend analysis. BMJ 2000;321:351-4.

4 Pierce JP, Gilpin EA, Emery SL, et al. Has the California tobacco control program reduced smoking? JAMA 1998;280:893-9.

5 Farrelly MC, Pechacek TF, Chaloupka FJ. The impact of tobacco control program expenditures on aggregate cigarette sales: 1981-2000. J Health Econ 2003;22:843-59.

6 Pierce JP, White MM, Gilpin EA. Adolescent smoking decline during California's tobacco control program. Tobacco Control 2005;14:207-12.

7 Weintraub JM, Hamilton WL. Trends in prevalence of current smoking, Massachusetts and states without tobacco control programs, 1990 to 1999. Tobacco Control 2002;11:8-13.

8 Siegel M, Biener L. The impact of an antismoking media campaign on progression to established smoking: results of a longitudinal youth study. Am J Public Health 2000;90:380-6.

9 Sly DF, Trapido E, Ray S. Evidence of the dose effects of an antitobacco counteradvertising campaign. Prev Med 2002;35:511-8.

10 Farrelly MC, Healton CG, Davis KC, et al. Getting to the truth: evaluating national tobacco countermarketing campaigns. Am J Public Health 2002;92:901-7.

11 Farrelly MC, Davis KC, Haviland, ML, et al. Evidence of a dose-response curve between exposure to truth ${ }^{\circledR}$ antismoking ads and youth smoking prevalence. Am J Public Health 2005;95:425-31.

12 Bal D, Kizer KW, Felten PG, et al. Reducing tobacco consumption in California. Development of a statewide anti-tobacco use campaign. JAMA 1990;264:1570-4.

13 Balbach ED, Glantz SA. Tobacco control advocates must demand high-quality media campaigns: the California Experience. Tobacco Control 1998;8:397-408

14 Niederdeppe J, Farrelly MC, Haviland ML. Confirming "truth": more evidence of a successful tobacco countermarketing campaign in Florida. Am J Public Health 2004;94:255-7.

15 Pierce JP, Emery S, Gilpin E. The California tobacco control program: a long term health communication project. In Hornik RC, eds. Public health communication: evidence for behavior change. Mahwah, New Jersey: Lawrence Erlbaum Associates, 2002:97-114.

16 Givel MS, Glantz SA. Failure to defend a successful state tobacco control program: policy lessons from Florida. Am J Public Health 2000;90:762-7.

17 Tsaukalas TH, Glantz SA. Development and destruction and the first state funded anti-smoking campaign in the USA. Tobacco Control 2003;12:214-20 
18 Maibach EW, Cotton D. Moving people to behavior change: a staged social cognitive approach to message design. In: Maibach E, Parrott RL, eds. Designing health messages. Thousand Oaks, California: Sage, 1995:41-64.

19 Rimer BK. Perspectives on intrapersonal theories of health behavior. In Glanz K, Rimer BK, Lewis FM, eds. Health behavior and health education. San Francisco: Jossey Bass, 2002:144-63.

20 Rosenstock IM. Historical origins of the health belief model. Health Educ Monogr 1974;2:1-8.

21 Rosenstock IM, Strecher VJ, Becker MH. Social learning theory and the health belief model. Health Education Quarterly 1988;15:175-83.

22 Bandura A. Social foundations of thought and action: a social cognitive theory. Englewood Cliffs, New Jersey: Prentice-Hall, 1986.

23 Bandura A. Social cognitive theory: an agentic perspective. Annu Rev Psychol 2001;52:1-26.

24 Baronowski T, Perry CL, Parcel GS. How individuals, environments and health behaviors interact. In Glanz K, Rimer BK, Lewis FM, eds. Health behavior and health education. San Francisco: Jossey Bass, 2002: 165-84

25 Prochaska JO, DiClemente CG. Stages of self-change of smoking: toward an integrative model of change. J Consult Clin Psychol 1983;51:399-405.

26 Prochaska JO, Norcross JC, DiClemente CG. Changing for good. New York: William Morrow, 1994.

27 Prochaska JO, Redding CA, Evers KE. The transtheoretical model and stages of change. In: Glanz K, Rimer BK, Lewis FM, eds. Health behavior and health education. San Francisco: Jossey Bass, 2002:99-120.

28 Fishbein M, Ajzen I. Belief, attitude, intention, and behavior: an introduction to theory and research. Reading, Massachusetts: Addison-Wesley, 1975.

29 Cappella JN, Fishbein M, Horne R, et al. Using theory to select messages in anti-drug media campaigns: reasoned action and media priming. In: Rice RE Atkins CK, eds. Public communication campaigns, 3rd ed. Menlo Park, California: Sage Publications, 2001.

30 Fishbein M, Yzer MC. Using theory to design effective health behavior interventions. Commun Theory 2003;13:164-83.

31 Institute of Medicine. Speaking of health: assessing health communication strategies for diverse populations. Washington DC: National Academies Press, 2002.
32 lyengar S, Kinder D. The priming effect. In: News that matters: television and American opinion. Chicago, Illinois: University of Chicago, 1987:63-72.

33 US Bureau of the Census. Census 2000, http://www.census.gov/main/ www/cen2000.html (Accessed 2002)

34 Mowery PD, Farrelly MC, Haviland ML, et al. Progression to established smoking among U.S. youths. Am J Public Health 2004;94:331-7.

35 Farrelly M, Davis K, Haviland L, et al. Measuring the success of the truth ${ }^{\circledR}$ campaign with the National Youth Tobacco Surveys. Boston, Massachusetts: Presented at the National Conference on Tobacco or Health, December, 2003.

36 Hersey JC, Niederdeppe J, Evans D, et al. The theory of truth ${ }^{\circledR}$ : how counterindustry campaigns affect smoking behavior among teens. Health Psychol 2005;24:22-31.

37 Chriqui JF, Frosh M, Brownson RC, et al. Application of a rating system to state clean indoor air laws (USA). Tobacco Control 2002;11:26-34.

38 Chow GC. Tests of equality between sets of coefficients in two linear regressions. Econometrica 1960;28:591-605.

39 Jayatissa WA. Tests of equality between sets of coefficients in two linear regressions when disturbance variances are unequal. Econometrica 1977;45:1291-2.

40 Flay BR. Mass media and smoking cessation: a critical review. Am J Public Health 1987;77:153-60

41 Flora JA, Maibach E, Maccoby N. Role of mass media in health promotion. In: Breslow L, eds. Annual review of public health. Palo Alto, California: Annual Reviews, 1989

42 Flynn BS, Worden JK, Secker-Walker RH, et al. Mass media and school interventions for cigarette smoking prevention: effects 2 years after completion. Am J Public Health 1994;84: 1148-50.

43 McMullen KM, Brownson RC, Luke D, et al. Strength of clean indoor air laws and smoking related outcomes in the USA. Tobacco Control $2005 ; 14: 43-8$

44 Lindsey D, Niederdeppe J, Fahimi M, et al. LYTES follow-up \# 1 summary report: TRUTH campaign awareness and reactions, Report prepared for the Florida Department of Health, 2003. 